International Journal of Current Advanced Research

ISSN: O: 2319-6475, ISSN: P: 2319 - 6505, Impact Factor: SJIF: 5.995

Available Online at www.journalijcar.org

Volume 6; Issue 4; April 2017; Page No. 3534-3536

DOI: http://dx.doi.org/10.24327/ijcar.2017.3536.0309

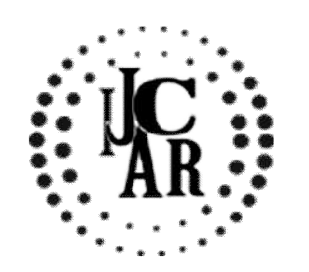

Research Article

\title{
RETAINED FOREIGN BODIES IN URINARY TRACT - OUR EXPERIENCE
}

\author{
Gnanasekaran $\mathrm{T}^{*}$, Gayathiri $\mathrm{M}^{2}$ \\ ${ }^{1}$ Department of Urology, Madurai Medical College \& Government Rajaji Hospital, \\ Madurai, Tamilnadu, India \\ ${ }^{2}$ Department of Obstetrics and Gynecology, Madurai Medical College \& Government Rajaji Hospital, \\ Madurai, Tamilnadu, India
}

A R T I C L E I N F O
Article History:
Received $8^{\text {th }}$ January, 2017
Received in revised form $6^{\text {th }}$ February, 2017
Accepted $19^{\text {th }}$ March, 2017
Published online $28^{\text {th }}$ April, 2017

\section{Key words:}

Foreign body, Retained DJ stent, Indigenous sex toys.

\begin{abstract}
A B S T R A C T
Introduction: Patients with foreign body in the urinary tract is an uncommon presentation in the urology clinics. Causes of this urinary tract foreign bodies are at times interesting. We have prospectively studied the incidence, causes, management and complications of the foreign bodies.

Materials \& Methods: Between January 2012-December 2016, 24 patients were treated for retained foreign body at Government Rajaji Hospital. Patients with retained foreign bodies in the urinary tract and those who have self introduced the foreign body were included in the study. All the patients were evaluated and diagnosis confirmed with radiological investigations. Treatment protocol discussed with the patients and all underwent surgical procedures. Results: 24 patients were included in the study. Out of the 24 , retained DJ stent was seen in 14 patients. They underwent Uretero renoscopy / ICL \& DJ stenting. Four patients had $\mathrm{TCu}$ in the bladder and Cystoscopic removal done. Three patients had encrustation over ruptured foley bulb. These patients underwent vesico lithotripsy along with F.B removal. Three patients had self introduced foreign body for sexual gratification. Meatotomy done for one and cystoscopic removal done for the other two.

Conclusion: Foreign bodies inside urinary tract are uncommon in both sexes. High index of suspicion is required in patients with LUTS. Patients should be adequately counseled if any foreign material is kept or left inside urinary tract. Foreign bodies may be used as an indigenous sex toys in both sexes. Treatment protocol should be individualized according to the type and site of the foreign body.
\end{abstract}

Copyright $₫ 2017$ Gnanasekaran T and Gayathiri M. This is an open access article distributed under the Creative Commons Attribution License, which permits unrestricted use, distribution, and reproduction in any medium, provided the original work is properly cited.

\section{INTRODUCTION}

Introduction of double $\mathrm{J}(\mathrm{DJ})$ stent, Foleys catheterization and $\mathrm{TCu}$ insertion are common to the medical practice. As the use of stents \& catheters became common, complications of retained foreign bodies came to light ${ }^{[1,2]}$. These stents, foley catheters, $\mathrm{TCu}$ are temporary and have to be removed ${ }^{[3,4,5]}$. Retained foreign bodies may be due to Iatrogenic - retained or migrating medical devices (Stent, Foleys, TCu), Inserted by the patient via the urethra for purpose of erotic stimulation, curiosity, or psychiatric illness, Trauma - Bullets etc. Bladder calculus formations around such long standing intra vesicular foreign bodies are well documented ${ }^{[6]}$. Patients with foreign bodies, present with Lower urinary tract symptoms (LUTS), recurrent urinary tract infections or with acute retention of urine (AUR). Thus, the need to have a system to avoid such complications was realized.

\section{*Corresponding author: Gnanasekaran T}

Department of Urology, Madurai Medical College \& Government Rajaji Hospital, Madurai. Tamilnadu, India
Study was undertaken to find out the causes, evaluation, diagnose without delay and management of these foreign bodies inside urinary tract.

\section{MATERIALS AND METHODS}

Patients presented or referred as retained foreign bodies in the urinary tract to urology clinics in our hospital from Jan 2012Dec 2016 were included in the study. Patients unaware of foreign bodies in the urinary tract, retained for more than 3 months and self introduced foreign bodies were included in the study. Informed written consent obtained. 24 patients attended urology clinic. Out of 24 one patient presented in the casualty with AUR. All patients undergone routine clinical examination, urinalysis, blood investigations, USG, $\mathrm{X}$ ray KUB. CECT taken when required. Surgical procedure planned after having discussion with patients. After removal of foreign bodies few required new DJ stents .Follow up and removal of these stents done after 3-4 weeks. 


\section{RESULTS}

Of the 24 patients, $14(58.5 \%)$ were retained DJ Stents inserted during previous ureteroscopic procedures, pelvic surgeries [Figure 1].
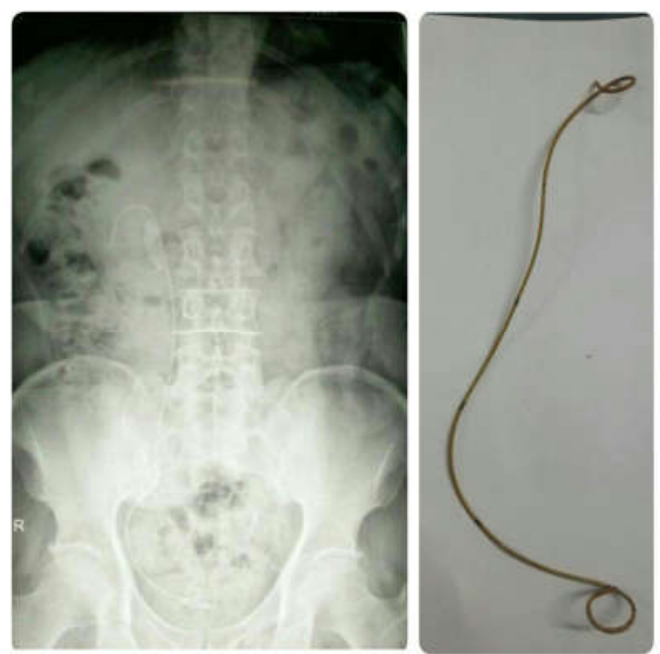

Figure 1 Retained DJ Stent

Four patients $(16.7 \%)$ had migrated $\mathrm{T}-\mathrm{Cu}$ [Figure 2] and three foreign bodies $(12.5 \%)$ were inserted by patients for sexual gratification [Figure $3 \& 4$ ].
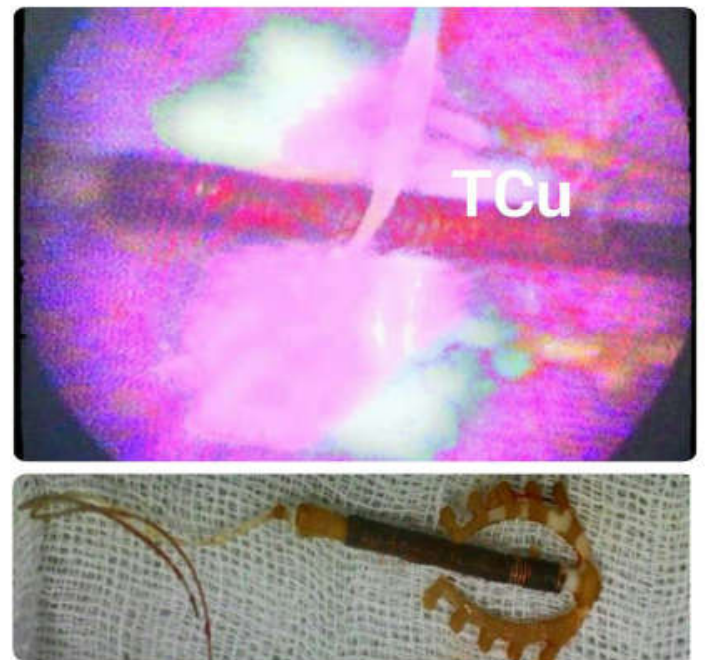

Figure 2 Migrated copper T in Bladder

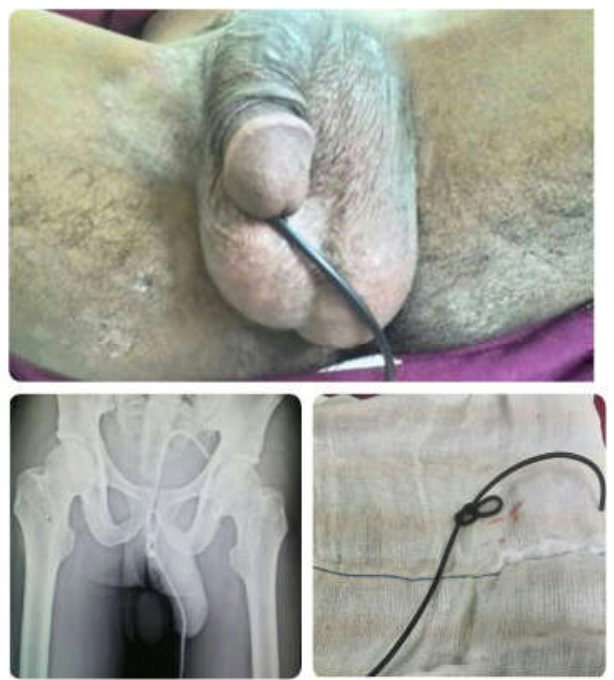

Figure 3 Electric wire in bladder
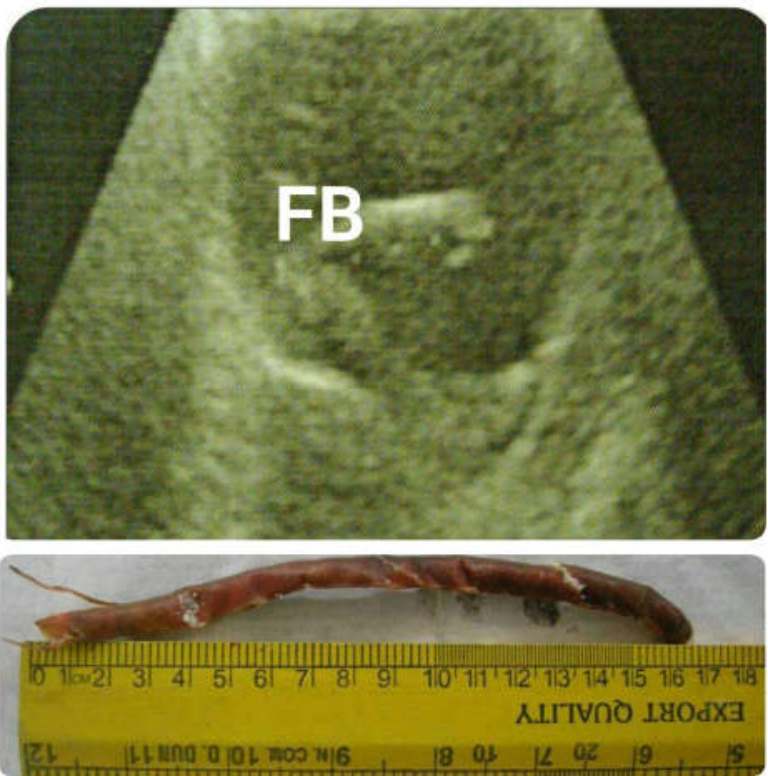

Figure 4 Vegetable foreign body in bladder

Three patients (12.5\%) had encrustations over ruptured Foley bulbs. Clinical and demographic factors of patients presented with foreign bodies are shown in [Table 1].

Table 1 Clinical and demographic factors of patients presented with foreign bodies

\begin{tabular}{ccc}
\hline FOREIGN BODY & SEX & NO. OF PATIENTS \\
\hline DJ STENTS & MALE -11, & 14 \\
COPPER T & FEMALE -3 & 4 \\
FOLEY BULB & FEMALE & 3 \\
ELECTRIC WIRE & MALE & 1 \\
KAJAL PENCIL CAP & MALE & 1 \\
VEGETABLE & FEMALE & 1 \\
\hline
\end{tabular}

All patients were given appropriate antibiotics and analgesics after admission. Ureterorenoscopy, intracorporeal lithotripsy done for retained DJS. Old stents were removed and fresh stenting done as per urology protocol for smooth passage of insignificant residual calculus and ureteric healing. Cystoscopy and removal of migrated $\mathrm{T}-\mathrm{Cu}$ done with forceps. Meatotomy and Foleys catheterisation is done for the foreign body inserted in the urethra. Urethral dilatation and cystoscopic removal done for the other 2 foreign bodies. Vesico lithotripsy was done for calculus over ruptured foley bulbs ${ }^{[7,8]}$. All patients were followed until patients were symptom free and removal of DJ Stents and urinary catheters.

\section{DISCUSSION}

Majority of patients in the urology OPD are those with lower urinary tract symptoms (LUTS). They may present with voiding symptoms like straining to void, poor stream and interruption of urinary stream or with storage symptoms like frequency, dysuria, urgency sometimes with hematuria. Patients with foreign bodies also will have these symptoms often overlooked. Careful past history like previous procedures, clinical suspicion may clinch the diagnosis. Common etiologies for these foreign bodies are Iotrogenic introduced. These are double J Stents which has to be inserted in almost all uretroscopic, pelvic and renal surgeries. However, retained stents not only cause increased morbidity, but can also be of significant medico legal importance. 
Accurate record keeping in the form of well-maintained logbooks as well as stent cards issued to patients have been tried. A computerized tracking registry was initially proposed by Monga et al. in 1995. Similarly, a computerized ureteric stent retrieval system was described by McCahy and Ramsden in 1996. Computer based stent registry with patient directed automated SMS and letter generator may avoid the menace of retained DJ stents (Nitin Sudhakar Kekre et al). Foleys catheters introduced in chronically bedridden patients like paraplegia. $\mathrm{TCu}$ insertion is one of the most successful family planning programs. All these foreign body insertion, mechanism of action, importance of removal of these materials are usually well explained to the patients. Still retained foreign bodies are unavoidable. Reasons may be the lack of documentation regarding the insertion, patient's unawareness about the presence of stent despite documentation in the discharge summary or medical reports and rarely, patient being unaware of the fact that the stent needed to be changed or removed. This was especially common in surgeries performed in emergency setting and intraoperative consults from other departments. Some patients default follow ups and end up with retained foreign bodies. Presentation of these patients may be acute or with LUTS. Few may present in the emergency clinic with acute retention of urine or with urosepsis. Sometimes foreign bodies in the lower genitourinary tract are self-inserted via the urethra as the result of Autoerotism, exotic impulses, psychometric problems, sexual curiosity, or sexual practice while intoxicated, aid to voiding \& no reason ${ }^{[9]}$. In our study we encountered 3 patients. One inserted electric wire [Figure 3], one inserted kajal pen cap and a women inserted vegetable foreign body [Figure 4]. Polyembolokoilamania is the act of inserting foreign objects into bodily orifices and can be classified as Paraphilia if done for sexual pleasure (Paul fedoroff et al, University of Ottawa, Archives of sexual behaviour 02/14).

Diagnosis is usually done with clinical suspicion, USG KUB, X-Ray KUB [Picture 3]. CECT may be required to know the extent of encrustation over these neglected foreign bodies. Management of these foreign bodies are immediate administration of urinary antibiotics thus avoiding urosepsis. Treatment should be individualised and depends upon the type and position of the foreign body. Endourological procedures are usually suffice, some may need auxiliary procedures like Extra corporal lithotripsy (E.S.W.L) ${ }^{[10]}$. During discharge of the patients with non absorbable catheters or materials physician should emphasize the importance of follow up and removal of the devices once it served its purpose.

\section{CONCLUSION}

Non absorbable medical devices are common armamentarium in urological and Obstetrics practice. Creation of awareness and education about the devices inserted, follow up and removal when required are of utmost importance to avoid patients with neglected foreign bodies.
Foreign bodies may be used as an indigenous sex toys in both sexes for sexual arousal. ${ }^{[11]}$ High index of suspicion in LUTS patients, prompt antibiotics to avoid urosepsis are required. Treatment protocol should be individualized according to the type and site of the foreign body.

\section{References}

1. Sagar Sabharwal, Anisha R Macaden, Nitin Abrol, Rajiv Paul Mukha, Nitin Sudhakar Kekre. A novel computer based stent registry to prevent retained stents: Will patient directed automated short message service and letter generator help? Indian Journal of Urology, Volume 30, issue 2 (2014) Page 150-152.

2. Monga M, Klein E, Castañeda-Zúñiga WR, Thomas R. The forgotten indwelling ureteral stent: A urological dilemma. J Urol 1995; 153:1817-9.

3. Dietrick DD. Issa MM. Kabalin JN. Bassett JB. Intravesical migration of intrauterine device. $J$ Urol 1992: 147: 132-134.

4. Yalcin V. Dernirkesen 0, Alici B. Onol B. Solok V. An unusual presentation of a foreign body in the urinary bladder: a migrant intrauterine device. Urol Int 1998: 61: 240-242.

5. Caspi B. Rabinerson D. Appleman Z. Kaplan B. Penetration of the bladder by a perforating intrauterine contraceptive device: a sonographic diagnosis. Ultrasound Obstet Gynecol 1996: 7: 458-460.

6. Noble JG, Chapple CR. Formation of a urethral calculus around an unusual foreign body. $\mathrm{Br} J$ Urol 1993; 72:2489

7. Priya Padmanabhan, Ryan C. Hutchinson, W. Stuart Reynolds, Melissa Kaufman, Harriette M. Scarpero, Roger R. Dmochowski. Approach to Management of Iatrogenic Foreign Bodies of the Lower Urinary Tract Following Reconstructive Pelvic Surgery. The Journal of Urology, Volume 187, issue 5, May 2012, Pages 1685-1690.

8. A Van Ophoven, JB de Kemion. Clinical management of foreign bodies of the genitourinary tract. J Urol, 164 (2000), pp, 274-287.

9. DK Pal, AK Bag. Intra vesical wire as foreign body in Urinary Bladder. Int Braz J Urol, 31(2005), pp 472474.

10. Y. Dakkak, A.janane, T.Ould-ismail, M.Ghadouane, A.Ameur, M.Abbar. Management of encrusted Ureteral stents. African Journal of Urology, Volume 18, Issue 3, September 2012, Pages 131-134.

11. G Vezhavendan, R Jeyaraman. Unusual foreign body in Urinary bladder. A case Report. The Internet Journal of Urology. 2006 Volume 4 Number 2.

\section{How to cite this article:}

Gnanasekaran T and Gayathiri M (2017) ' Retained Foreign Bodies In Urinary Tract - Our Experience', International Journal of Current Advanced Research, 06(04), pp. 3534-3536.

DOI: http://dx.doi.org/10.24327/ijcar.2017.3536.0309 